NOTAS

\title{
ADAM FERGUSON Y LOS ORÍGENES DEL CONCEPTO DE SOCIEDAD CIVIL \\ José Fernández Santillán*
}

En el campo de la filosofía política contemporánea el concepto de 'sociedad civil' ha retomado un lugar de primera fila, desplazando a temas que estuvieron en el candelero durante las décadas de los setenta y ochenta, como la posmodernidad y el multiculturalismo. Esta reanimación se debe, en buena medida, a la liberación de los países del Este europeo. Vale decir, el renacimiento de la sociedad civil, como tema de estudio y como fenómeno práctico, tiene que ver con la caída de los regímenes comunistas. Lo interesante del asunto es que el fracaso del socialismo autoritario no sobrevino, como se suponía, del enfrentamiento con las potencias occidentales, sino por un proceso interno de inconformidad de sus propias sociedades. El asfixiante

* Departamento Académico de Ciencia Política, ITAM. corsé de hechura burocrática que a fuerza se les impuso terminó por exacerbar los ánimos de millones y millones de seres humanos. Como alternativa a la falta de canales de expresión reconocidos e institucionalizados, surgieron agrupaciones civiles clandestinas que fueron creando redes solidarias de resistencia. Esas redes sirvieron lo mismo para defender a las personas encarceladas injustamente que para distribuir publicaciones elaboradas por militantes del movimiento de inconformidad. A esas formas alternativas de organización se les dio el nombre de civil society, usando, así, literalmente, la expresión anglosajona. Como dice Ignatieff: "Los grupos de estudio filosóficos, los sótanos y cuartos de caldera, los círculos de plegaria en las criptas de las iglesias y las reuniones de los grupos no oficiales en bares y trastiendas fueron 
NOTAS

vistos como una sociedad civil en embrión. En esas instituciones encubiertas sobrevino la educación en la libertad y las energías liberadoras que llevaron al triunfo en 1989. En las revoluciones de esos años en Hungría, Polonia, Rumania, Alemania del Este, Checoslovaquia y el Báltico, la sociedad civil triunfó sobre el Estado."

Como era de esperarse, en los primeros momentos de la lucha se puso más atención a los aspectos coyunturales del proceso. Fue sólo después, cuando las cosas se fueron asentando, que se pudieron calibrar la densidad teórica y las profundas raíces históricas que el concepto 'sociedad civil' encerraba. Dicho concepto está íntimamente relacionado con el desarrollo de la filosofía política moderna. Sin exagerar, en el vocablo sociedad civil se conjugan por lo menos tres siglos de reflexión política.

La figura más conocida en esa trayectoria, desde luego, es Hegel. Este pensador desdobló el vocablo societas civilis (que indicaba tanto la condición política como la condición civilizada), utilizado por los miembros de la escuela del derecho natural como Hobbes, Locke y Rousseau,

${ }^{1}$ M. Ignatieff, "On Civil Society: Why Eastern Europe's Revolution Could Succeed”, Foreign Affairs, 1995, 74, 2, p. 128. para así distinguir el momento político (politischen Staat) del momento civil (bürgerliche Gesellschaft). Para Hegel la sociedad civil era una etapa intermedia entre la familia y el Estado; era una primera forma de integración colectiva en el ascenso de la eticidad (Sittlichkeit). La sociedad civil indicaba en su sistema de pensamiento la esfera de la pluralidad y de la libertad subjetiva, mientras que el verdadero propósito de la integración humana sólo era localizable en el Estado, unidad política en la que se alcanzaba la libertad objetiva.

De la compleja composición de la sociedad civil hegeliana, dividida en tres diferentes niveles, es decir: a) el sistema de necesidades, b) la administración de justicia, y c) la administración pública y las corporaciones, Marx sólo tomó de esa composición el primer nivel, o sea, el sistema de necesidades que se refiere al mundo de la economía. De esta forma, de acuerdo con el autor de El Capital, la sociedad civil es la base real sobre la cual se eleva la colosal superestructura jurídica y política a la que corresponden determinadas formas de conciencia individual y colectiva. De acuerdo con este pensador, es en la sociedad civil donde se presentan las verdaderas contradicciones sociales que son las contradicciones de clase. 
"Llegados a una cierta etapa de desarrollo las fuerzas productivas entran en contradicción con las relaciones de producción Es en ese momento cuando se abre una etapa revolucionaria.” Su idea es que la revolución proletaria tendría la tarea de echar abajo el Estado burgués, que no representaba, como lo creía Hegel, la superación de las contradicciones sino por el contrario un instrumento de dominación de una clase social sobre otra. La meta, en consecuencia, era alcanzar la sociedad sin clases, libre de toda dominación político-estatal.

Cómo no recordar que durante largas décadas, sobre todo en el período de la Guerra fría, en el ambiente académico, tanto en el Viejo como en el Nuevo mundo, dominó la discusión en tomo a la relación filosófica Hegel-Marx, uno de cuyos ejes fue la sociedad civil.

Hoy que el marxismo cayó en desgracia junto con los regímenes comunistas, se ha dado pie a la búsqueda de otros y más propositivos antecedentes del concepto de sociedad civil; búsqueda que intenta traspasar los antiguos cánones académicos. Pues bien, en esta etapa posmarxista en la que acudimos al renacimiento de la sociedad civil, aparece la figura de Adam Ferguson, uno de los miembros más connotados de la Ilustración escocesa. La sustancia de sus estudios en tomo al tema que nos interesa quedó plasmada en su libro Un ensayo sobre la historia de la sociedad civil, cuya primera edición está fechada en 1767.

El texto contiene una serie de elementos por demás interesantes para el conocimiento de la sociedad civil, sobre todo en su vertiente civilizatoria. Para hacer esto posible, Ferguson adopta el método histórico: no piensa, como los iusnaturalistas, que el origen y la fundamentación de la sociedad civil estén en la libre y voluntaria aceptación de los individuos, quienes por medio de un contrato establecen un orden político. Ferguson no es individualista ni contractualista. Su punto de partida son los individuos ya asociados.

Lo que conduce a los hombres a reunirse es el instinto natural (apetitus societatis). Esta postura teórica queda expuesta en las primeras páginas de su obra: "La humanidad debe considerarse en grupo, como siempre ha existido, cada experimento en esta materia debe hacerse considerando sociedades completas, no individuos aislados." ${ }^{2}$ Como la mayor

${ }^{2}$ Adam Ferguson, Un ensayo sobre la historia de la sociedad civil, 1974, Madrid, colección dirigida por Francisco Javier Conde, edición revisada y corregida por Juan Rincón Jurado, Instituto de Estudios Políticos, Clásicos Políticos, p. 6. 
NOTAS

parte de los escritores de su época, se apoya en los testimonios de quienes visitaron las tierras recién descubiertas, o sea, toma como base para el desarrollo de su estudio los testimonios que llevaron a Europa los viajeros que visitaron otros continentes: “Tanto en las primeras como en las últimas relaciones recogidas en cada rincón de la Tierra, se representa a la humanidad como agrupada en tribus $\mathrm{y}$ asociaciones, $\mathrm{y}$ al individuo unido siempre por simpatía a un grupo, y probablemente en oposición a otro. [...] Estos hechos deben reconocerse como la base de nuestro razonamiento sobre el hombre.”3 Se opone a las tesis de Hobbes y Rousseau. Sobre el primero dice que hay quienes "hacen consistir el estado de naturaleza en guerras perpetuas, originadas en la lucha por el dominio y el interés, donde cada individuo mantiene una lucha aislada con sus semejantes, y donde el capricho de un semejante era la señal de batalla”. ${ }^{4}$ Es 'la guerra de todos contra todos', descrita en el Leviatán.

A Rousseau lo incluye entre los escritores que "han representado a la humanidad en su condición primitiva, como poseída de una sensibilidad meramente animal, sin ejercitar ninguna de las facultades que le hacen superior a los brutos, sin ninguna

${ }^{3}$ Ibidem, p. 5.

${ }^{4}$ Ibid., p. 4. unión política, sin ningún medio de expresar sus sentimientos e incluso sin poseer ninguna de las ideas y pasiones que la voz y el gesto son tan adecuados para expresar". ${ }^{5}$ Hace mofa de la figura del 'buen salvaje' y de aquella primera condición incorrupta en la que se desenvolvió -según afirma Rousseau- el género humano hasta que 'condiciones externas' lo obligaron a salir de ella. Como el propio ginebrino dejó apuntado en sus escritos, en especial en el Discurso sobre el origen de la desigualdad, él no se apoyó en referencias científicas o empíricas; su construcción filosófica parte de una hipótesis del origen de la humanidad, así como los estudiosos de la naturaleza elucubran acerca del origen del mundo.

Ferguson, en contraste, desecha la hipótesis que trataba de reconstruir situaciones que la evidencia histórica y científica no respalda. Lo que acepta es la inclinación hacia el progreso y la perfección. Al asumir una idea progresiva de la historia, Ferguson se aleja del comunitarismo antiguo. De hecho, la perspectiva desde la cual concibe a la 'sociedad civil' tiene que ver sobre todo con la parte civilizatoria del vocablo. Por tanto, cuando habla de la "historia de la sociedad civil” se refiere, particularmente, a la historia de la sociedad

${ }^{5}$ Idem. 
civilizada que en etapas sucesivas abandonó la condición primitiva.

Para Ferguson, en las cosas humanas no hay afinidades ni aversiones; lo que se presentan son sentimientos combinados: en ocasiones hay convergencias y en otras divergencias. Una primera y elemental operación humana consiste en que casi por instinto el hombre se identifica con los miembros del grupo de pertenencia y siente repulsión hacia los individuos extraños a la propia comunidad.

Griegos y romanos, por ejemplo, catalogaban como 'bárbaros' a los pueblos que les eran extraños. Los llamaban 'bárbaros' porque cuando los oían hablar emitían sonidos incomprensibles, parecidos al bar, bar, bar. El bárbaro es, en principio, aquel a quien no se entiende. Es la manera en que se designa a la persona con la cual no hay punto de contacto, no hay posibilidades de comunicación.

La sociedad civil -entendida, precisamente, como sociedad civilizada- apareció en medio de la lucha entre los pueblos que, en su afán por sobrevivir, trataron de no quedarse en el atraso. Ésa fue la virtud de Grecia y Roma: supieron salir de la condición primitiva para dominar a los pueblos incivilizados que merodeaban en su alrededor y, aunque los bárbaros eran fieros y sanguinarios, no pudieron con la mayor fuerza organizada de la civilización: "Los pueblos incivilizados en general, aunque pacientes para soportar las durezas y las fatigas, aunque sean amantes de la guerra y aptos por sus estratagemas y valor para sembrar el pánico en los ejércitos de un enemigo mejor organizado, sin embargo, a lo largo de una continua lucha, siempre deben sucumbir ante las artes superiores y la disciplina de las naciones más civilizadas.”6 Esta idea alude a la relación conflictiva de las naciones más avanzadas y los pueblos primitivos. Se deduce de la lectura que Ferguson quiso llamar la atención sobre el hecho de que en la antigüedad los pueblos incivilizados eran más numerosos y, con todo y la fuerza organizativa de las naciones civilizadas, éstas se encontraron permanentemente asediadas y en conflicto con los bárbaros; en tanto que, para los tiempos en los que él escribió, los pueblos incivilizados se habían reducido en número mientras que la cantidad de las naciones civilizadas iba en aumento.

Ferguson sabía que también en el interior de las sociedades modernas se presentaban sentimientos combinados de afinidad y discordia. Para que las sociedades no degeneren en la autodestrucción, las coincidencias deben ser mayores que las divergencias. En el caso de las naciones civilizadas

\footnotetext{
${ }^{6}$ Ibid., p. 120.
} 
NOTAS

como Roma, advierte que fueron constantes las discrepancias entre patricios y plebeyos, pero las riñas entre ambos bandos fueron sabiamente encauzadas para que contribuyeran a la grandeza de la república. La decadencia sobrevino cuando las divergencias ya no pudieron ser armonizadas.

De acuerdo con Ferguson, hay cuatro cosas que provocan la disgregación de la sociedad. De una parte, los extremos de la anarquía y la tiranía, porque puede regresarse al desorden mutuamente destructivo, o puede concentrarse el mando en un hombre arbitrario que abuse del poder. De otra parte, el conflicto en el interior de la sociedad puede brotar por la carencia de justicia, 'no existe paz en ausencia de justicia': la sociedad puede vivir perfectamente en medio de querellas y opiniones contrarias, pero no en medio de delitos que queden sin castigo; si las faltas no se penalizan como marca la ley, entre ofensores y ofendidos se presenta un permanente estado de hostilidad, más parecida a la condición salvaje que a la civilizada.

La justicia para Ferguson no sólo tiene que ver con la aplicación escrupulosa de la ley; ella supone el principio de equidad, de suerte que, cuando hay fuertes desequilibrios entre las fortunas de los miembros de la sociedad, los conflictos inevita- blemente se incrementan. La estabilidad y el orden vienen a menos.

Otro motivo de disolución es que los hombres dejen de interesarse por los problemas colectivos y adopten una posición al mismo tiempo pasiva y egoísta. En este renglón Ferguson recupera el valor de la 'virtud' antigua, esto es, la entrega del individuo al bien colectivo.

Pero, si bien admira las virtudes antiguas, reconoce la diferencia entre la agregación comunitaria y el asociacionismo moderno. La distinción radica en que en el mundo antiguo el individuo estaba subordinado a la comunidad, en tanto que en el mundo moderno el sujeto tiene derechos y espacios propios.

Ferguson, como autor moderno reconoce el valor del individualismo: "Si el bien público es el principal objetivo de los individuos, es también cierto que el bien de los individuos es el fin primordial de la sociedad civil. ¿Porque en qué sentido puede la comunidad disfrutar el bienestar, si sus miembros, considerados independientemente, no son felices?"7 Luego entonces, si bien acepta la virtud política, no cree que en ella se agote la figura del individuo.

\footnotetext{
${ }^{7}$ Ibid., p. 72. En el aspecto de la 'virtud republicana' se nota la influencia de Montesquieu en Ferguson.
} 
Al diferenciar el mundo antiguo del moderno, se percata de que en el pasado la actividad más apreciada era la guerra, en tanto que en el presente los hombres tienen en gran estima el comercio. Recurre a la frase de Tácito, según la cual en un tiempo remoto los hombres fueron 'más generosos con su sangre que con su sudor'.

Siguiendo un método que no oculta la influencia de Montesquieu, Ferguson describe el carácter de los pueblos de acuerdo con los factores climáticos, la situación geográfica, las costumbres y la creación de riqueza, para mostrar la evolución o el estancamiento. No obstante, dejando traslucir cierta relación con las ideas de Rousseau, cuando indica que la sociedad civil apareció al surgir la propiedad. Sobre este asunto es famosa la frase que se encuentra al inicio de la segunda parte del Ensayo sobre la desigualdad. "El primero que habiendo demarcado un terreno, pensó afirmar: esto es mío, y encontró personas bastante simples para creerlo, fue el verdadero fundador de la sociedad civil." ${ }^{8}$ La propiedad en Rousseau sirve para marcar el inicio de la sociedad civil en cuan-

\footnotetext{
${ }^{8}$ Jean Jacques Rousseau, "Discourse sur l'origine et les fondaments de l'inegalité”, Oeuvres complètes, 1964, París, Gallimard, p. 164.
}

to sociedad civilizada, pero no todavía política porque ella, en el ámbito del iusnaturalismo, sólo puede fundamentarse en la estipulación de un acuerdo.

En el libro de Ferguson se encuentra una frase muy similar a la de Rousseau, pero dirigida a resaltar la sociedad civil, no propiamente en su faceta civilizada sino desde el aspecto político: “Quien dijo primero: 'Me apropiaré de este campo y lo dejaré a mis herederos', no se dio cuenta de que estaba estableciendo las bases de las leyes civiles y de las instituciones políticas." ${ }^{9}$

Hay pues una semejanza y una diferencia entre Rousseau y Ferguson. La semejanza estriba en que para ambos la propiedad es el punto de partida de la sociedad civil; la diferencia consiste en que en el ginebrino se trata de la sociedad civil en cuanto sociedad civilizada, mientras que en el escocés se trata de la sociedad civil en cuanto sociedad política.

Al cuadro comparativo habría que agregar otra distinción: para Rousseau el surgimiento de la propiedad marca el inicio de la sociedad civil corrupta; para Ferguson la aparición de la propiedad es el inicio de la institucionalidad política, cuyo destino puede ir desde la pronta decadencia hasta el auge según la nación de que se trate.

\footnotetext{
${ }^{9}$ Adam Ferguson, op. cit., p. 155.
} 
NOTAS

En tomo a estas diferencias entre las perspectivas de Rousseau y Ferguson sobre la sociedad civil seguramente habrá muchas explicaciones, pero entre ellas no se puede pasar por alto que uno y otro asumen posiciones filosóficas distintas: Rousseau contempla la sociedad civil en dos diferentes niveles, o sea, como sociedad civilizada y como sociedad política. Para él la sociedad civil -en cuanto civilizada-proviene de un largo proceso evolutivo, cuya expresión definitiva es la aparición de la propiedad. Luego de eso, y por la necesidad de institucionalizar las relaciones de poder, se implanta la sociedad civil en cuanto condición política por medio de un contrato. Por lo que hace a Ferguson, la sociedad civil en cuanto civilizada surge también de un largo e intrincado proceso evolutivo pero, al no ser iusnaturalista, evita justificar la situación política a través de un contrato y, por ello, tiene que echar mano del expediente de la propiedad para marcar la aparición de las instituciones políticas.

Hablando de las instituciones políticas, Ferguson adopta la tipología de Montesquieu: república (subdividida en democracias y aristocracias), monarquía y despotismo. Pero, curiosamente, a diferencia de Montesquieu, Ferguson no se inclina por alguna de esas constituciones, sino por la que llama 'gobiernos equi- librados'. Para él, este tipo de gobiernos es una combinación de las formas simples, a saber, la monarquía, la aristocracia y la democracia; o sea, hace referencia al 'gobierno mixto’ que Montesquieu ubica en el 'gobierno gótico' o la monarquía constitucional.

Ferguson argumenta su preferencia por los 'gobiernos moderados' de la siguiente forma: "En los gobiernos propiamente equilibrados el interés popular al encontrar la contraposición del príncipe y de los nobles establece un balance de intereses, de forma que la libertad pública y el orden público puedan existir." ${ }^{\prime 0}$ Su predilección por este tipo de combinaciones no es una simple especulación. Por el contrario, había ejemplos históricos relevantes de naciones que lograron esa difícil amalgama: "Roma e Inglaterra, bajo gobiernos equilibrados, uno con tendencias a la democracia y el otro inclinado a la monarquía, han resultado ser los más grandes legisladores entre las naciones. Roma legó las bases y en gran parte la superestructura de su código civil al continente europeo. Inglaterra, en su isla, ha llevado la autoridad y el gobierno de la ley a un grado de perfección que jamás había sido logrado antes en la historia de la humanidad." 11

\footnotetext{
${ }^{10}$ Ibid., p. 206.

${ }^{11}$ Ibid., p. 208 (subrayado mío).
} 
Roma e Inglaterra lograron el equilibrio de las fuerzas sociales representadas, respectivamente, por el principio democrático (el pueblo), por el aristocrático (los nobles) y por el monárquico (el rey), teniendo como complemento el gobierno de las leyes. Esto significa que cualquier poder en la sociedad civil, no importando su procedencia, debe estar sometido a la norma jurídica, porque de otra manera el poder que estuviese por encima de la ley se convertiría en un poder incontrolado. Si eso llegase a suceder se pondría en peligro la sobrevivencia de la sociedad.

La lección de Ferguson es inequívoca: si se desea que haya una sociedad civil bien constituida ésta debe contar con instituciones políticas sólidas, todo ello bajo el imperio de la ley.

Aun así, no debe quedar la impresión de que cumplidos esos requisitos la sociedad quede a salvo de problemas. Por el contrario, Ferguson descubre una tensión en la sociedad moderna entre el compromiso con la comunidad y el interés individual; entre la virtud política y el lucro económico; es la disputa entre el ideal político y la lógica del mercado.

Un estudioso del concepto de sociedad civil, Víctor Pérez-Díaz, ha señalado lo siguiente: "Los filósofos escoceses fueron muy conscientes de la tensión existente entre el mercado y el sistema político, como es particularmente obvio en Ferguson.”12 Este escritor no permaneció neutral ante el problema. Como afirma Ronchetti: "el factor que Ferguson considera decisivo como criterio civilizatorio no es tanto la cuestión económica autónomamente considerada, sino la calidad de la participación política de los ciudadanos en la vida de la nación”. ${ }^{13}$ Así es, en efecto, para Ferguson el factor determinante de la sociedad civil es el político. Seguramente al ver el incremento de la conflictividad social reflexionó acerca de la importancia de la cuestión institucional. Si la sociedad civil no cuenta con órganos de gobierno y leyes que le permitan procesar los conflictos, su vida será corta. Éste, ni más ni menos, es un reto que en nuestro tiempo ha cobrado una impresionante actualidad.

${ }^{12}$ Víctor Pérez-Díaz, "The Possibility of Civil Society”, en John A. Hall (ed.), Civil Society, 1995, Cambridge, G. B., Polity Press, p. 91.

${ }^{13}$ Emanuele Ronchetti, "Gli utilitaristi”, en Luigi Firpo (ed.), Storia delle Idee Politiche Economiche e Sociali, 1980, Turín, Utet, vol. II, p. 567. 